\title{
Biodegradable stents: truly biodegradable with good tissue harmony
}

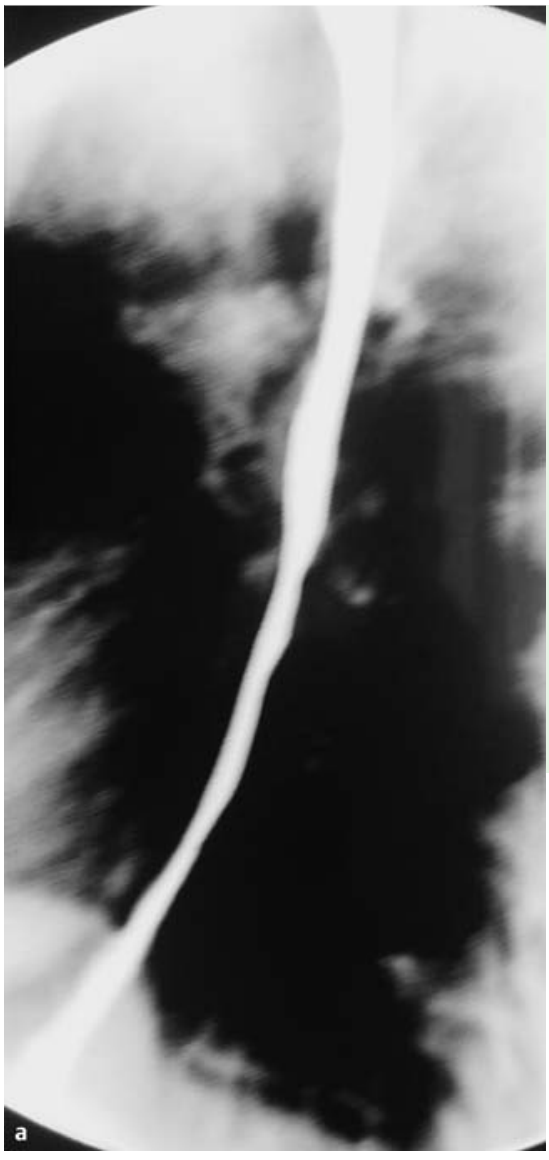

A 48-year-old man presented to our hospital with corrosive (sulfuric acid)-induced esophageal and pyloric strictures and a barium study showing narrowing of a long segment in the distal esophagus

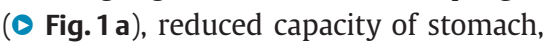

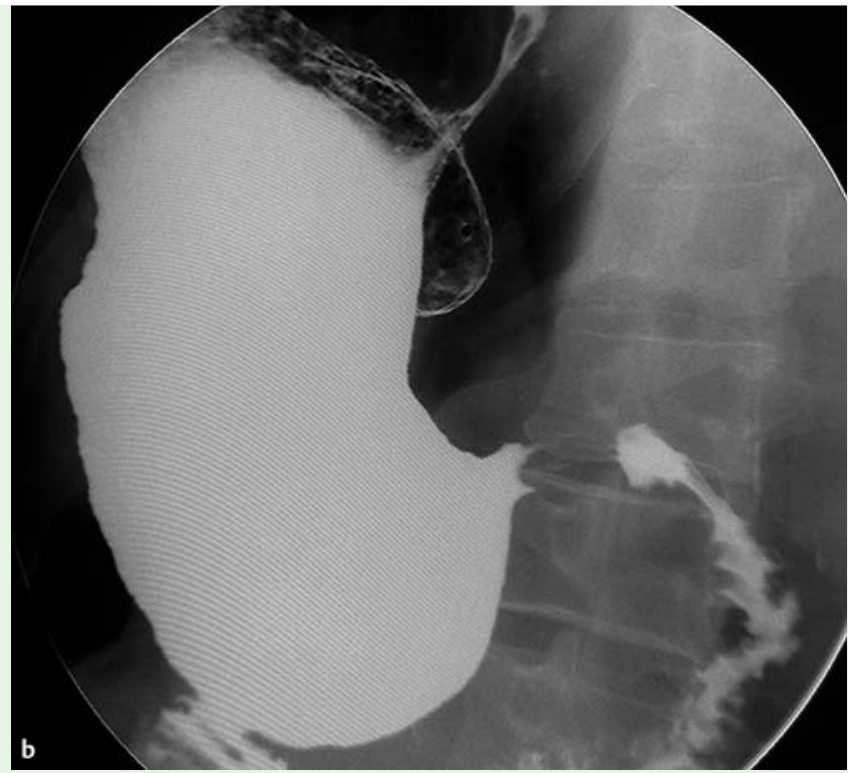

Fig. 1 a Barium swallow in a 48-year-old man with history of corrosive (sulfuric acid)induced esophageal and pyloric strictures showing long segment narrowing of the thoracic esophagus with mucosal irregularity. b Barium meal examination showing reduced capacity of stomach with narrowing in the antropyloric region. and antropyloric narrowing ( Fig.1b). Balloon dilation (Boston Scientific, Natick, Massachusetts, USA) of esophageal and pyloric strictures was done over a period of 6 months. The pyloric stricture opened up, however, the esophageal stricture was refractory and the patient continued to have dysphagia. Therefore, an $80 \mathrm{~mm} \times$ $23 \mathrm{~mm}$ SX-ELLA esophageal biodegradable stent (ELLA-CS, Hradec Králové, Czech Republic) was placed across the narrowed segment of the esophagus. Endoscopy revealed complete degradation at 12 weeks, and after 4 months the patient had symptomatic recurrence requiring dilation ( Fig.2). After 6 months

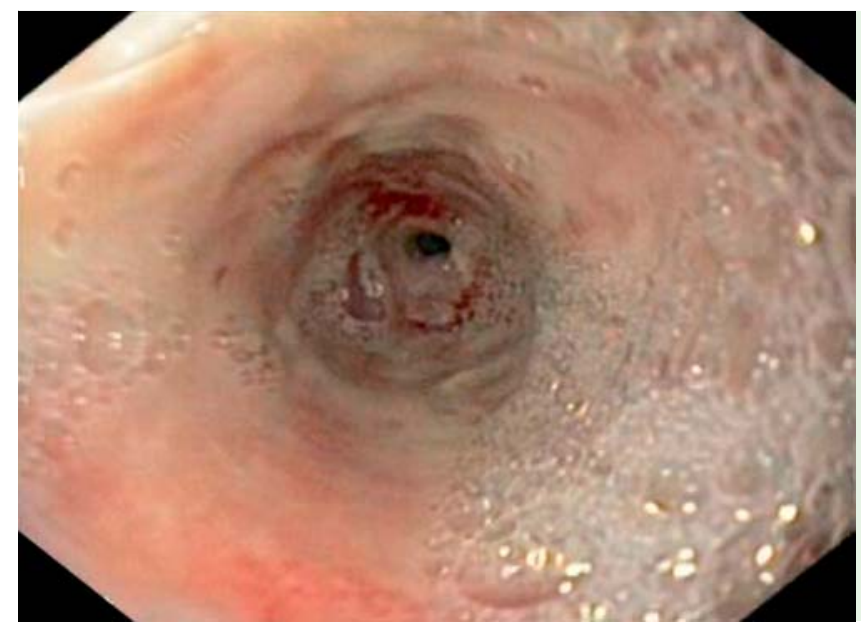

Fig. 2 Endoscopic view showing distal esophageal narrowing with no evidence of the biodegradable stent. of the placement of the biodegradable stent he underwent transhiatal esophagectomy with colonic transposition. The patient remained asymptomatic at follow-up after 6 months.

Macro/microscopic examinations revealed no evidence of stent material. The resected esophagus had a thickened wall

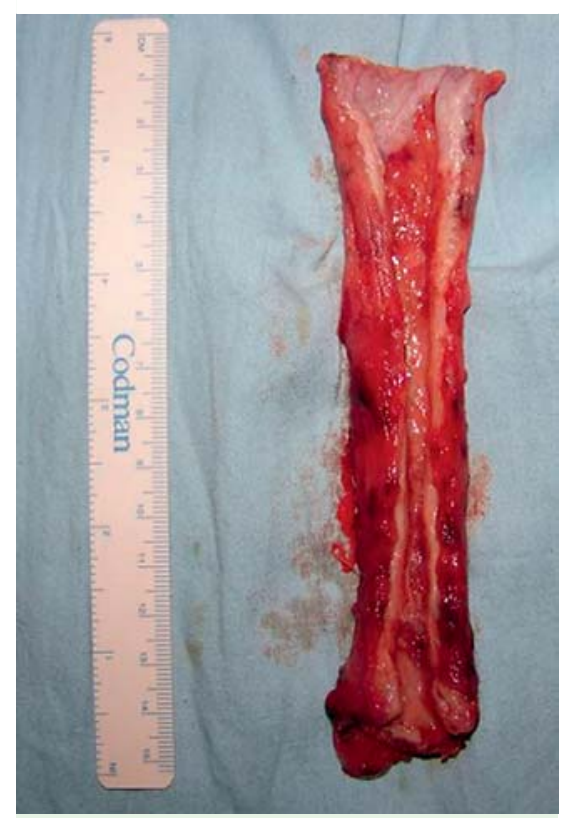

Fig. 3 Resected specimen of the esophagus showing ulcerated mucosa with no evidence of the biodegradable stent. 

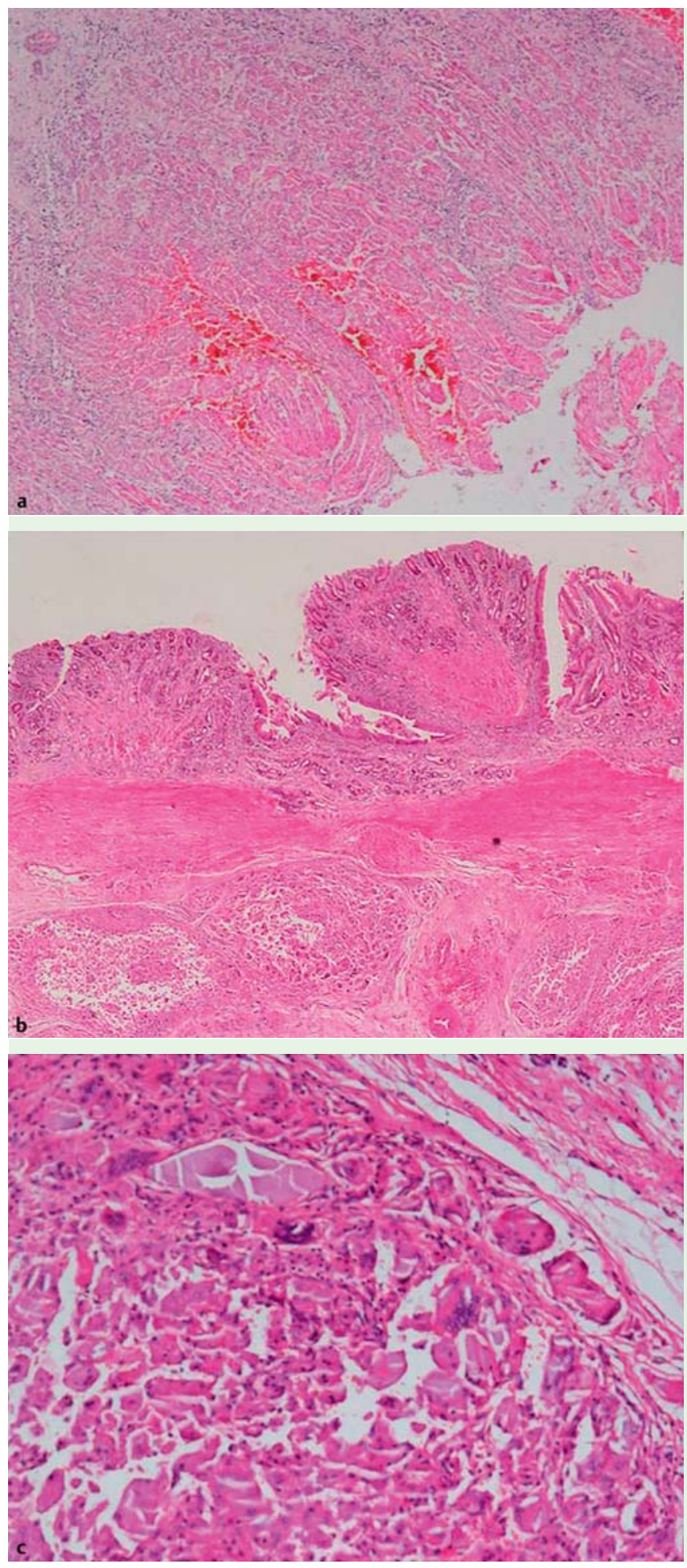

Fig. 4 a Low-power photomicrograph of the esophagus showing deep mucosal and replacement fibrosis of the remaining esophageal wall (hematoxylin and eosin, magnification $\times 250$ ).

b Low-power photomicrograph showing partly ulcerated and hyperplastic gastric mucosa. The submucosa shows presence of foreign body granulomas (hematoxylin and eosin, magnification $\times 150$ ).

c High-power photomicrograph showing the features of the granuloma: note the epithelioid histiocytes and the numerous multinucleated giant cells, some containing variable-sized, bluishcolored foreign bodies (hematoxylin and eosin, magnification $\times 500$ ). with ulcerated mucosa and narrowed lumen ( $\bullet$ Fig.3). On histological examination, the esophageal mucosa showed diffuse and deep ulcerations with marked submucosal fibrosis extending up to the muscularis propria ( $\bullet$ Fig.4a). The gastric mucosal lining (seen at the distal end in the figure) had deep ulcerations and many foreign body granulomas in the submucosa ( Fig. 4b,c).
The biodegradation and tissue compatibility of biodegradable stents has been evaluated in animal studies only. Bergsma et al. [1] implanted poly-L-lactic acid (PLLA) particles subcutaneously in rats, and found a foreign body reaction at 3 weeks, followed by resolution at 16 weeks. Gogolewski et al. [2] and Schakenraad et al. [3] studied degradation of subcutaneously implanted PLLA copolymers in mice and observed that the macrophage and giantcell infiltration decreased by $12-24$ weeks along with polymer degradation. There is no literature on the biocompatibility of biodegradable stents in humans and no reports of histological changes in the esophagus even in animal studies. Our report is the first in a human case showing histological evidence of complete degradation of a biodegradable stent with good biocompatibility and minimal tissue reaction in the resected specimen.

Endoscopy_UCTN_Code_CCL_1AB_2AC_3AD

\section{Competing interests: None}

\section{J. Basha ${ }^{1}$, S. Appasani ${ }^{1}$, K. Vaiphei ${ }^{2}$, V. Gupta ${ }^{3}$, K. Singh' ${ }^{1}$, R. Kochhar ${ }^{1}$}

1 Department of Gastroenterology, Postgraduate Institute of Medical Education and Research, Chandigarh, India

${ }^{2}$ Department of Pathology, Postgraduate Institute of Medical Education and Research, Chandigarh, India

${ }^{3}$ Department of Surgery, Postgraduate Institute of Medical Education and Research, Chandigarh, India

\section{References}

1 Bergsma JE, Rozema FR, Bos RRM et al. In vivo degradation and biocompatibility study of in vitro pre-degraded as-polymerized polylactide particles. Biomaterials 1995; 16: 267-274

2 Gogolewski S, Jovanovic M, Perren SM et al. Tissue response and in vivo degradation of selected polyhydroxyacids: Polylactides (PLA), poly (3-hydroxybutyrate) (PHB), and poly (3-hydroxybutyrate-co-3-hydroxyvalerate) (PHB/VA). J Biomed Mater Res 1993; 27: $1135-1148$

3 Schakenraad JM, Nieuwenhuis P, Molenaar I. In vivo and in vitro degradation of glycine/ DL-lactic acid copolymers. J Biomed Mater Res 1989; 23: 1271-1288

Bibliography

DOI http://dx.doi.org/

10.1055/s-0032-1326111

Endoscopy 2013; 45: E116-E117

(c) Georg Thieme Verlag KG

Stuttgart · New York

ISSN 0013-726X

\section{Corresponding author}

\section{Professor R. Kochhar}

Department of Gastroenterology

PGIMER, Sector 12

Chandigarh - 160012

Fax: +91-172-2744401

dr_kochhar@hotmail.com 